\title{
Experiences of Having a Parent with Serious Mental IIlness: An Interpretive Meta-Synthesis of Qualitative Literature
}

\author{
Anna Källquist ${ }^{1} \cdot$ Martin Salzmann-Erikson $\mathbb{D}^{2}$
}

Published online: 13 May 2019

(c) The Author(s) 2019

\begin{abstract}
Objectives Previous research found that burdens are put on relatives to patients with serious mental illness. A majority of the studies have described the situation of being a husband/wife or parent of someone who is mentally ill. However, little is known about the perspective of childhood experiences and the effect on adult life from having a parent with mental illness. Hence, the purpose of this review was to investigate experiences of having a parent with serious mental illness.

Methods We used a qualitative interpretive meta-synthesis. Five relevant databases were chosen: Cumulative Index to Nursing and Allied Health Literature, MEDLINE, PsycINFO, PubMed and Psychology and Behavioral Sciences Collection. We found 4302 studies in our initial search. Fourteen met the inclusion criteria and the quality assessment.

Results The findings are presented in four themes: (1) Growing up in a dysfunctional home environment; (2) The child's feelings and thoughts; (3) The need of support; and (4) The lingering effects in adult life.

Conclusions We found that experiences of growing up in a dysfunctional home can result in relational issues later in life and that the need for support can persist into adult life. This has implications for clinical practice when encountering these patients.
\end{abstract}

Keywords Adult children $\cdot$ Children $\cdot$ Experiences $\cdot$ Mental illness $\cdot$ Parent

There is a growing body of literature that recognizes the importance of investigating the perspective of the burden put on relatives to patients with mental illness (Ewertzon et al. 2010; Mignone et al. 2017; Richert et al. 2018). A qualitative interview study reported that relatives often felt worried and stressed from being afraid that the family member would commit suicide (Treanor et al. 2013). That study also found that, even though relatives accepted and comprehended the situation resulting from the illness, they still expressed feelings of anger, frustration and hopelessness. Another study found that relatives demonstrate

Research involving Human Participants and/or Animals: Not applicable.

Anna Källquist

anna.kallquist@telia.com

1 Löwenströmska Hospital, Section North, Forensic Psychiatry Care, 19489 Upplands Väsby, Sweden

2 University of Gävle, Faculty of Health and Occupational Studies, Department of Health and Caring Sciences, SE-801 76 Gävle, Sweden difficulties in letting go of control when ill relatives are expressing suicidal thoughts. Likewise, Weimand et al. (2013) pinpointed the difficulties for relatives in finding a balance between letting the ill person live an independent life and managing insights into the ill person's treatment, daily life and economy. The situation of the patients also affects the relatives' own life. Stjernswärd and Östman (2008) found that relatives to persons with depression expressed feelings of not being able to live their own lives autonomously. The needs of the relatives became secondary and relatives constantly felt worried, angry, frustrated and exhausted. Moreover, the relatives were also made to take the majority of the responsibility at home and felt that their role and wellbeing affected their private, social and work life. Ewertzon (2012) reported conflicting emotions among siblings to people with psychosis, as they wanted to be present for their sibling, but at the same time, strived for independence in their own life. It was reported that being engaged in the life of the ill sibling was time consuming and required an adjustment in their life to the condition of the sibling, which resulted in feelings of being lonely.

Relatives are also engaged in the professional care of the ill person and studies that have reported their experiences demonstrate diverging experiences. In a qualitative study by 
Askey et al. (2009), relatives felt that hospitals were sometimes experienced as frightening and that patient's basic needs were not cared for. However, if the sick person received care that was professional, adequate and of a high standard, the relatives' stress and burden decreased. Deficiencies in these increased the relative's guilt and burden when their sick relative was admitted to the hospital. Relatives wished that the psychiatric care would concern itself more with long-term needs, such as a functioning daily life with social content. Sometimes, the relatives felt angry and upset that the psychiatric care services were not paying attention and did not listen to them, and that they were not taken seriously when expressing their concerns. Relatives felt that their participation in the care was not as extensive as it could be, even though they had much knowledge about their relative's wellbeing and daily life. Relatives wished that the health care staff had been more attentive and supportive and had shown more respect. Nordby et al. (2010) collected data from focus groups, in which the participants had a relative that had recently received a severe psychiatric diagnosis. The relatives felt that they had a lack of knowledge and experience in handling the situation, which made them feel helpless. The families felt a need for emotional and practical help. The relatives wanted to be able to express their experiences concerning the well-being of their sick family members to the health care staff. They wanted the staff to see the person, not only the illness. Similarly, Askey et al. (2009) reported that it was important to receive information about the illness, the treatment, early signs of deterioration and how to respond to difficult behaviors that the relative might show.

Other research has focused on the role of being a parent and being diagnosed with a mental illness. A focus group study showed that parents experienced a double burden, both managing the illness and raising their children (Jones et al. 2016). Ill parents felt that there was a negative view towards people with mental illness and they wished that their condition could be less stigmatized. Furthermore, some of the parents had a fear that their children would inherit the illness. The parents felt that their children gave them great joy and motivated them to, for example, get up in the morning and receive treatment for their illness. In contrast, another qualitative study showed that parents with very severe mental illness experienced that the illness affected their lives, in periods, to such an extent that they were not able to take care of themselves or that they lacked the ability to take care of their children's needs (Parrott et al. 2015). The parents experienced pain because they did not have as good a relationship as they wished to have with their children. When they were separated from their children, they felt great sorrow and pain, but some stated that they were thankful that the children did not have to see them when they felt their worst. The parents who had contact with their children felt that their children motivated them to get better. The parents found it difficult to explain their illness and hospital admissions to the children. Few researchers have given attention to gender issues in this matter. However, a qualitative study by DiazCaneja and Johnson (2004) showed that mentally ill women who became mothers felt motivated to stay in contact with the psychiatric care services and receive treatment to avoid deterioration. They wanted to maintain their responsibility as parents. The children made them feel better and happier, and were sometimes seen as the reason that they were still alive. The parents were worried that their illness had affected the children in a negative way and that their children would inherit the illness. The parents experienced that there were prejudices that a person with mental problems could not be a good parent, so they did not tell other people about their psychological problems. In the same study, mothers feared losing custody of their children due to their mental illness.

Being a child and a next of kin to a mentally ill parent is associated with difficulties and challenges for the child. A child is particularly exposed compared with other relatives because the child is dependent on its parent for safety and care, and the parent's ability to cater for this can be decreased by mental illness. These aspects were put forth in the study by Jewell et al. (2009). They showed that when the family received family education, they learned about the illness and how they could support their sick family member. This decreased their stress and provided them with a larger social network. Hence, family education facilitates the opportunity to express grief, as well as feelings of guilt, shame and loneliness. Furthermore, Jewell et al. also identified that family education led to an awareness of the early signs of deterioration and a better understanding of medications and could thus decrease the risk of relapse. Preventive family interventions were investigated in a doctoral dissertation by Pihkala (2011), with a specific focus on children who grew up with a parent with a mental illness. Pihkala emphasized that these children were at risk of developing psychological and other problems, both as children and as adults. However, the research investigating children's perspectives of growing up with a mentally ill parent is sparse.

Adult psychiatric care has often failed to give these children support. In some countries, preventive family intervention has been used for a few years (Pihkala 2011). As we have outlined in this introduction, being a relative to a person with serious mental illness is challenging and places burdens on the relatives. We define serious mental illness to include schizophrenia, bipolar disorder and major depressive disorder since these disorders infer and impair the life in a profound way (SAMHSA 2016). However, the situation of being a relative as a child is less explored in research. Thus, the purpose of this review was to investigate experiences of having a parent with serious mental illness. Three research questions guided the review: (1) What experiences do adults, 
who grew up with a parent with serious mental illness, have from childhood? (2) How is adult life affected by the experience of growing up with a parent with serious mental illness? (3) How do adults, who grew up with a parent with serious mental illness, reflect on the support that they received during their childhood and as adults?

\section{Methods}

This review is a qualitative interpretive meta-synthesis. The method is well-recognized and is useful for synthesizing the findings of a group of qualitative studies into an enhanced understanding of the phenomenon of inquiry (Estabrooks et al. 1994; Finfgeld-Connett 2014; Gonsalves et al. 2017; Sandelwski and Barroso 2007). The qualitative approach was used to gain narratives of lived experiences. Furthermore, we adhered to the four-step description of the synthesis process of Evans (2003); (1) Gathering the sample; (2) Identifying key findings; (3) Relating themes across studies; and (4) Describing the phenomenon.

\section{Criteria for Inclusion and Exclusion}

First, we determined the unit of analysis (Evans 2003). In order to do so, we set the following criteria for inclusion: (a) the study is qualitative (including mixed-method studies), (b) the study is empirical, (c) the participants are aged 18-64, (d) the participants have a parent with a serious mental illness (psychosis, depression, and/or bipolar disorder), and (e) the article is written in English, German, Swedish or Norwegian. Only one criterion for exclusion were set: (a) low quality in the critical assessment valuation.

\section{Literature Search}

Next, we located the studies (Evans 2003). Five relevant databases were chosen: Cumulative Index to Nursing and Allied Health Literature (CINAHL), MEDLINE with full text, PsycINFO, PubMed and Psychology and Behavioral Sciences Collection. We consulted a librarian at the university and determined relevant keywords and also decided that we should not restrict the search to any specific year. The first exposure (A) concerned the illness, for example, psychosis and psychotic disorder. The second exposure (B) concerned the relationship, for example, parent and adult children. The third exposure (C) concerned the qualitative and subjective experiences, for example, feelings and experiences. The keywords varied slightly in the different databases. A detailed chart of the keywords is shown in Fig. 1. Within each exposure, the Boolean term OR was used to widen the search as much as possible. Since each exposure resulted in several hundred thousand hits, it was not possible to scan the results at this exposure level. We narrowed the search by using the Boolean term AND across the exposures, which resulted in no more than 1296 hits per search. In all five databases, we found 4302 studies. These were assessed on the basis of their title and 4087 were excluded, as they were found not to be relevant for the review. The remaining 215 articles were reviewed on the basis of their abstract and 182 were excluded, mainly due to the fourth criterion for inclusion. The remaining 33 articles were read fully and an additional 19 were excluded, since they had the perspective of children's, parents', or siblings' experiences and some of the articles had quantitative study designs. The sample was limited to 14 articles, which were assessed according to quality.

\section{Quality Assessment}

To assess the quality of the studies, we used the screening template that was used by Salzmann-Erikson and Dahlén (2017). The template covers critical questions, for example, "Does the introduction provide an adequate description of the selected investigation?", "Are the selection criteria relevant to the study's purpose?", "Is the data systematically collected?", "Are the results credibly described?", and "Are the study's ethical aspects discussed?". In total, the template has 25 questions. Each question can be answered with Yes ( 1 point) or No (0 points). An article with a sum of $0-17$ points is given a score of "Low", an article with a score of 18-20 points is given a score of "Medium" and an article with 21-25 points is given a score of "High". One study was scored as low and excluded. Four studies were assessed as medium and the remaining nine as high. This step is termed 'selecting the sample', in accordance with Evans (2003).

\section{Data Analysis}

The second step, according to the descriptive synthesis of Evans (2003), is identifying key findings. The Result section in each of the articles $(N=14)$ was read repeatedly in order to become familiarized with the data. The key findings of each article were copied and pasted into a separate document and read and reviewed line-by-line. The key findings were then condensed into shorter sentences or words that summarized these key findings. In total, we extracted 302 key findings. The third step, according to Evans, is to compare the key findings for their similarities and differences. Key findings with similar content were collected and grouped into themes. We engaged in frequent discussions during this phase. From this iterative process of grouping, we decided that four themes covered the whole data set. An overview of the key findings and themes is shown in Table 1. Within each theme, we identified nuances, which resulted in sub-themes. For example, the first 
Fig. 1 PRISMA 2009 Flow Diagram. From: Moher D, Liberati A, Tetzlaff J, Altman DG, The PRISMA Group (2009). Preferred Reporting Items for Systematic Reviews and Meta-Analyses: The PRISMA Statement. PLoS Med 6(7): e1000097. 10.1371/ journal.pmed1000097

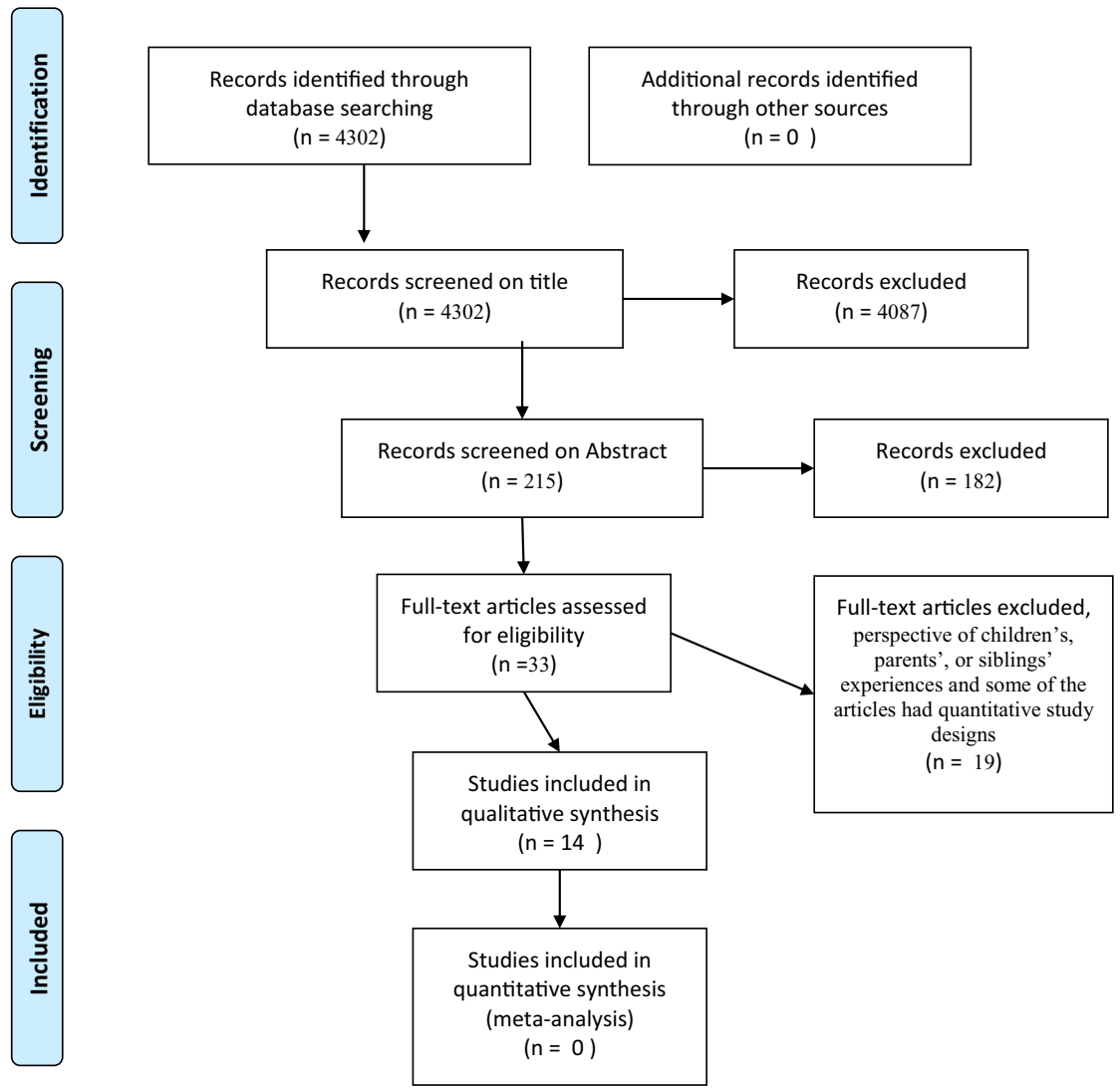

theme was termed "Growing up in a dysfunctional home environment", but key findings about experiencing "a deviant parent" and "covering up in silence" differed from each other, which thus resulted in two different sub-themes. The sub-themes and the key findings were reviewed and further compared to the data set as a whole. The last step, according to Evans, is to present a descriptive synthesis of the phenomenon and this is presented in the Results section.

\section{Results}

The analysis of the 14 articles gave four different themes: Growing Up in a Dysfunctional Home Environment, which had five sub-themes, The Child's Feelings and Thoughts, which had two sub-themes, The Need of Support, which had two sub-themes and The Lingering Effects in Adult life, which had three sub-themes.

\section{Growing up in a Dysfunctional Home Environment}

This theme concerns the behavior of the ill parents and how the adult children perceived the parent during their childhood. The theme also concerns what happened at home and the situation within the family. The theme is categorized into five sub-themes: $a$ different parent, the illness and its effect on the parental role, reversed roles and responsibility, do not talk about the illness and inability to comprehend the situation.

\section{A different parent}

It was reported that the children, early in life, felt that the ill parent and their family were different. The adult children stated that in the first years of school they discovered that their parent was somehow different than other parents. Not being able to understand the parent's illness caused difficulties in distinguishing symptoms of the illness from whom the parent was as a person (Baik and Bowers 2006). The participants related that they knew something was not right about their parent, but they did not know about or understand the illness and they did not separate the parent and the illness (Foster 2010). The participants stated that it was when they met their friends' parents that they realized how different their own parent was (Kadish 2015; Mechling 2016). Even at an early age, the children were aware of a judgmental view towards people with a mental illness (Murphy et al. 2015a). Some described longing for an 'ideal 


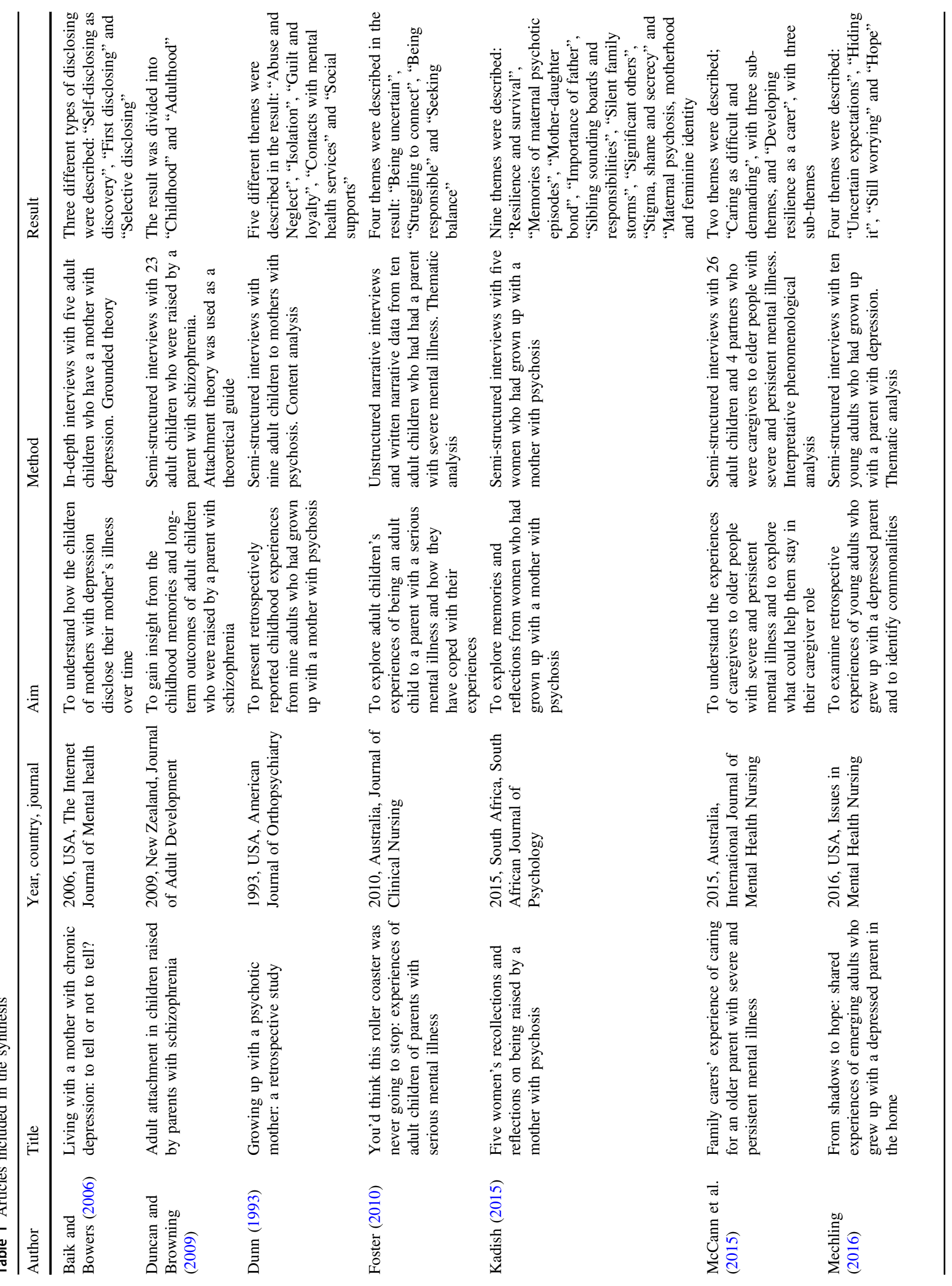




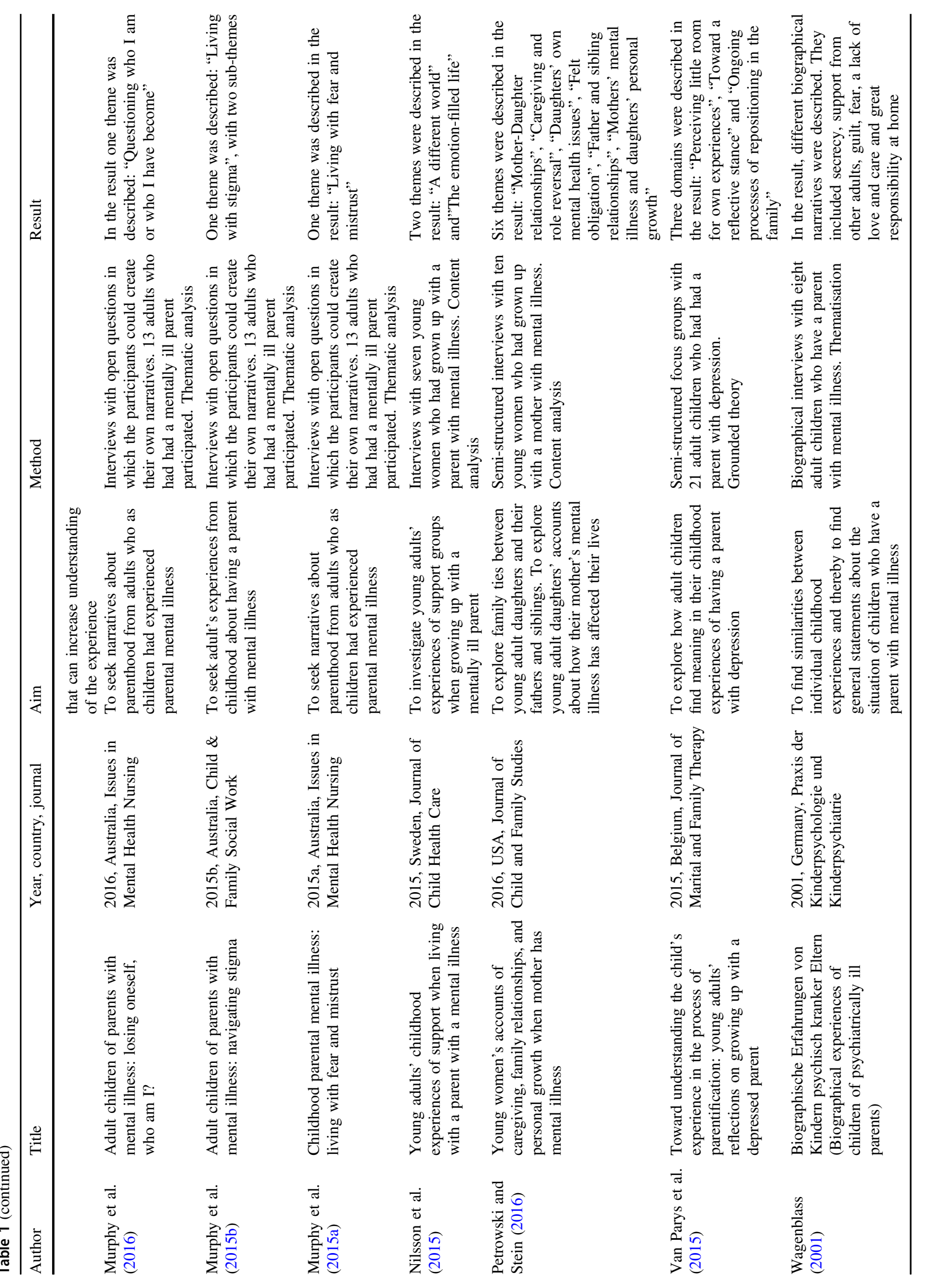


parent' that cared, worried and set boundaries, and were envious of other children (Wagenblass 2001).

\section{The illness and its effect on the parental role}

The participants who had a parent suffering from psychosis reported that they had strong memories of the parent being paranoid, with delusions that also included the child. Some children had experienced dangerous and frightening situations in which the parent was physically abusive, while others mostly experienced that the parent had been absent and neglected them (Duncan and Browning 2009; Dunn 1993). The parent was sometimes physically absent due to hospitalization, but sometimes the parent was mentally absent. The parents were described as ignoring the children's basic needs for love, care, protection and attention. In some homes, the children were never bathed and did not have suitable or clean clothes. The children were sometimes a part of the parents' delusions, such as paranoid thoughts about the children being kidnapped. The participants sometimes had difficulties taking friends over due to their parent's bizarre behavior (Dunn 1993; Wagenblass 2001). Hence, due to the parents' defected perception of reality, the illness affected the parental role. One person in the study by Baik and Bowers (2006) reported that the mother did not want to be bothered, so the girl and her siblings made themselves ready for school. The participants experienced that it was difficult to have a good relationship with the parent, partly because the illness affected the parents' behaviour and parental role in a negative way. Some participants had had a close relationship when the parent was feeling better, which though worsened when the parent became more ill (Foster 2010). Participants who had a mother with psychosis had memories from the mother's psychotic episodes, which made the children very uncomfortable, and they learned from an early age to set emotional and psychological boundaries towards their mother (Kadish 2015). Some parents had delusions concerning the healthy parent or other people. This created worry and fear among the children and sometimes also family conflicts (Murphy et al. 2015b), which affected the parental role.

\section{Reversed roles and responsibility}

Participants reported that the roles at home were reversed during their childhood, since they felt responsible for the family's wellbeing. They supported the ill parent, which burdened them. The reversal of roles at home involved their taking care of the parent, instead of the parent taking care of them. The children felt that they had more control over their everyday life than the parent did. The siblings though were a great source of support for each other. They shared the same experience of growing up with the mentally ill parent, which could only be fully understood by those who had grown up in the same family (Petrowski and Stein 2016). When the parent did not have the ability to care for the children's needs, it was often the children who, at an early age, took care of both the parent and the younger siblings (Dunn 1993; Foster 2010). Wagenblass (2001) described how the oldest sibling adopted a parental role and was in charge of the household and of the younger siblings. There were also examples of participants who reported that the siblings took turns guarding the mother. The participants gained support from their siblings and they worked as sounding boards; someone you could talk with about the parent. Older siblings took care of younger siblings and the sick parent when the parent was not able to do so (Kadish 2015). The participants who were younger siblings stated that they felt protected by their older siblings. The older siblings knew more about the illness and they also tried to hide the parent's problems from the younger siblings. Interviewed older siblings felt an overwhelming responsibility to protect younger siblings and they deliberately hid information. The older siblings sometimes felt considerable guilt and sadness that they had not been able to protect their siblings well enough (Murphy et al. 2016). The children worried about the parent and felt responsible for the parent and for what happened at home (Nilsson et al. 2015).

\section{Do not talk about the illness}

The adult children stated that during their childhood they did not talk about their parent's illness. It was described as being embarrassing to have a parent who was deviant. The children tried to keep this secret in order to not lose friendships and upset the family. Participants had experienced that they were told as children, especially by the parents, not to talk about the illness with people outside the family (Baik and Bowers 2006). It was stated that no one informed them properly about the illness. One participant indicated that the mother was admitted to the hospital, but no information was given about when she would be coming back (Dunn 1993). The children often kept the parent's illness a secret out of fear of meeting prejudices, of being pushed away, and of being humiliated, and because they wanted to protect the parent. Talking about the illness was seen by the family as being disloyal and could lead to anger (Kadish 2015; Murphy et al. 2015a; Nilsson et al. 2015). The participants reported that both the sick and the well parent, as well as other relatives, did everything to veil the illness (Mechling 2016). Some participants stated feelings of isolation and confusion since they lacked information (Murphy et al. 2015a). Furthermore, participants described being restricted in talking about the illness, due to taboos and in order to not worsen the existing burden. They felt a desire to talk about their experiences, but felt that they had to protect their parent (Van Parys et al. 2015; Wagenblass 2001). 


\section{Inability to comprehend the situation}

The participants reported that it was difficult to comprehend what was taking place in their family during their childhood. They were unable to comprehend the parent's illness and were not able to provide answers to others when asked about their situation and their parents (Baik and Bowers 2006). The children sometimes experienced frightening situations when the parent was psychotic. These situations were not explained and this led to confusion concerning their own reality. The children sometimes felt that they had two realities, one at home and one outside of the home, such as at school (Dunn 1993). The children were unable to comprehend that the parent had a mental illness, hence they could not separate the parent from the illness (Foster 2010; Murphy et al. 2016). Some parents could, in affect, make to the children such remarks as that they would be better off without them, and the children found it difficult to interpret such statements (Mechling 2016). The fact that no one explained the parent's illness made it difficult for the children to understand what was happening (Nilsson et al. 2015; Van Parys et al. 2015).

\section{The Child's Feelings and Thoughts}

This theme concerns the child's feelings and thoughts during their childhood, in which they grew up with a parent with mental illness. The theme is categorized into two subthemes: fear and guilt and alienation.

\section{Fear and guilt}

The children were sometimes afraid of the parent and they often felt worried for the parent, for example, that the parent would hurt himself/herself (Wagenblass 2001). Situations arose that were characterized by anger and abusiveness from the parent; the participants described such situations as imbued with fear, especially when the parent had been experiencing a psychosis (Dunn 1993; Kadish 2015). They also had feelings of uncertainty, because they did not know what would happen or which mood the parent would be in (Foster 2010). The children lived with fear and mistrust, and these feelings were also sometimes still present in their adult life. Not understanding the illness and the parents' behaviour, together with a feeling of being detached from others, made the fear even greater. There was fear and worry concerning the parent's security, and sometimes that the parent would commit suicide. Some also felt fear concerning their own safety when the parent was verbally or physically abusive. The parents' unpredictable behaviour led to both fear and mistrust, they did not know when and if the parent would hurt himself/herself or them. Sometimes, the parent had paranoid thoughts and was afraid. This could affect the child's emotional wellbeing (Murphy et al. 2015b). In seven of the studies, the participants reported that they had felt a lot of guilt during childhood. The children stated that they had thought it was their fault that the parent felt bad, and they were ashamed (Baik and Bowers 2006). The adult children described feelings of guilt, which sometimes were associated with a loyalty towards the parent. In some families, the children were separated from their parent and they then felt a great deal of guilt that they had left the parent, though they also at the same time felt relieved. The children also felt guilty because they thought that they had caused or worsened the parent's illness (Dunn 1993). The children felt guilty because they were not able to make the parent feel good (Kadish 2015; Murphy et al. 2016; Nilsson et al. 2015; Wagenblass 2001). It was difficult to manage the parent's crises, and the children felt that they were not allowed to think that it was difficult. It was the parent who was ill and the children felt that they did not have the right to feel bad. They also felt guilty if they talked to someone outside the family about the illness, though this was guilt mixed with feelings of relief (Van Parys et al. 2015).

\section{Alienation}

The children felt isolated from their family and also from society and peers. They felt alone and different from other, "normal" people. They were ashamed of their parent's behaviour and of their family situation. Sometimes, they were teased and people talked about, and laughed at, their parent (Dunn 1993; Foster 2010). The parent's behaviour was unpredictable and very embarrassing when it was disclosed outside the family. They had noticed that their parent was different from other adults, according to society's expectations (Murphy et al. 2015a). The children sometimes felt anxiety, loneliness, isolation, sadness and anger (Wagenblass 2001). Participants described a lack of support in their childhood and that they had no one to trust, which gave them strong feelings of loneliness (Van Parys et al. 2015). The children sometimes did not feel loved and cared for. They did not get the support that children should receive (Kadish 2015). It could be difficult to get close to someone and some children felt that they had fewer opportunities than other children. It was also reported that the participants, in their childhood, had problems knowing who they were and that they sometimes lost touch with reality. It could be difficult to know what feelings they were supposed to feel. They felt responsible for the parent's mental state and for how the parent acted in public. There was a feeling of mistrust towards the parent. The children did not see their own value; their needs and wellbeing were not as important as those of others (Murphy et al. 2016). 
Some participants reported that it was as teenagers that they fully understood how different their parent was compared to others. This affected them; tolerance for their experiences decreased and they started to question their situation. They reported that, in their teenage years, they were emotionally and psychologically overwhelmed by their own experiences. They felt lost and unsure of who they were and felt that they lived one life at home and another life outside the home. Being with other people outside of the home gave normality, but they were always aware that they would go back home to confusion and loneliness (Murphy et al. 2016). In their teenage years, they started to understand the parent's illness and their own feelings. They discovered more information about mental illness and could then understand their childhood experiences in a new way. The situation they had been used to and had seen as normal was seen in a new way when they started to understand the parent's illness. Some felt anger that they had not been informed about the illness. There was sometimes an inner conflict that concerned understanding the parent and also creating distance from the parent. They started to separate the parent from the illness. The participants sometimes realized as teenagers that the parent was not going to feel better, which they previously had hoped for. Some felt that it was important to feel that they were different than their parent. There was fear concerning inheriting the illness and not being able to enjoy life (Van Parys et al. 2015).

\section{The Need of Support}

This theme concerns the need for support and the support that was given when growing up with a parent with serious mental illness. The theme is categorized into two subthemes: The children's contact with persons other than the sick parent, which focuses on the child's perspective and Health care and support groups, which describes both the child's and the adult child's perspective.

\section{The children's contact with persons other than the sick parent}

One study showed that participants from families which had not separated seemed to have fewer problems. The children gained protection and normality when the healthy parent stayed in the family and/or when the children had close contact with relatives, such as grandparents (Duncan and Browning 2009). In one study, the adult children stated that very little was done to protect them from their psychotic parent. Some children told that the healthy parent sometimes came to the rescue, but in other cases neither of the parents provided attention and caring. They described the importance of other adults who gave support and help.
These other adults could be grandparents, neighbors or teachers. The children did not necessarily talk to these persons about their parent's illness, but they gave security and attention, and the children saw these persons as their rescue (Dunn 1993). Participants described having a close relationship to the other, healthy parent. They also had important support from other adults, such as grandparents, family friends and neighbors (Foster 2010). One study was made in South Africa, where the participants had a maid. These women gave the children considerable support. The participants saw these women as having been important for their survival. They cared for the children and took care of the household, and also protected the children from the parent when this was needed (Kadish 2015). In two of the studies with children who had a sick mother, the father's important role was described. He was seen as stable, independent and a person that could be trusted. However, they experienced that the father had problems in managing the situation with the sick mother. Sometimes the father was in denial and sometimes he distanced himself from the family. They also felt that he had not been able to help the children cope with their experiences. Some participants felt that they gave emotional support to the father (Kadish 2015; Petrowski and Stein 2016). It was reported that grandparents sometimes took over the parental role at home when this was needed. The children's friends could be a support, sometimes just by being there and sometimes by being someone that they could talk to about their experiences (Van Parys et al. 2015). Some participants experienced problems in talking to the school staff, whom they experienced as being hard to talk to and as not being supportive (Nilsson et al. 2015). A lack of social support was described, and that it was important to receive encouragement and support from other adults. One person reported that the grandmother had helped in maintaining normality in the family (Wagenblass 2001).

\section{Health care and support groups}

A negative view of the health care services was described in the studies. They had seen the parent being taken away to the hospital, without receiving any explanation. Some participants had visited their parent at the hospital, which led to fear, pain and guilt. Some experienced that the parent was not treated well in the hospital (Dunn 1993) and experienced that their parent had been hospitalized and heavily "drugged" (Mccann et al. 2015). As children, they themselves were subjected to bad comments from health care staff that gave feelings of guilt (Dunn 1993). The participants sometimes felt critical about the attitudes of the health care services towards them and experienced a lack of support and information (Foster 2010; Van Parys et al. 2015). However, they also stated that when the family and the 
health care services gave support, it was easier to continue being a caregiver. Discussing their feelings felt good (Mccann et al. 2015).

Participants reported that support groups had helped them to understand that the illness was not their fault and that others were in similar situations. The leaders of the support group became adults that could be trusted and gave support to the participants. It could sometimes feel tough and empty for the participants when the support groups ended (Nilsson et al. 2015). Furthermore, support groups facilitated a relief from the burden of responsibility (Wagenblass 2001). One participant met a therapist during late adolescence and was then able to understood that his mother had had a depression during his childhood, and he was then able to feel relieved from his feelings of guilt (Baik and Bowers 2006). Some participants had experienced that the mental health care services had invited the child to engage in a dialogue with the doctor, together with the family, and that this was positive. Therapy was also experienced as positive; it had helped the participants to reflect in a new way about themselves (Van Parys et al. 2015).

\section{The Lingering Effects in Adult Life}

This theme concerns how adult life is affected by growing up with a seriously mentally ill parent. The theme is categorized into three sub-themes: Relationships with the parent, relationships with others and health and personal growth.

\section{Relationships with the parent}

Some participants described having a loving relationship with their sick parent (Dunn 1993). Participants reported that their responsibility to take care of the parent continued into adulthood, which was demanding and resulted in guilt, anger and isolation from social activities with their own friends (Dunn 1993; Mccann et al. 2015). Participants struggled with setting both physical and emotional limits, but stated that therapy was helpful (Dunn 1993; Foster 2010). Feelings of fear in childhood were associated with mistrust of the parent and of others, and this mistrust was often also present in adulthood (Murphy et al. 2015b). Participants, when they became adults, often in some degree distanced themselves from their parent and family. Some participants felt an obligation to visit the parent more, while others had the opposite view, that they would like to have less contact with the parent (Petrowski and Stein 2016).

\section{Relationships with others}

Participants described difficulties with trust and intimacy with other people and expressed restrictions in having a functioning intimate relationship (Baik and Bowers 2006; Duncan and Browning 2009; Foster 2010). One participant shared that he could not have a relationship because all his energy was used in taking care of his mother. Participants felt that their childhood with the sick parent had affected their choice of partner. For example, they might find themselves in a relationship with someone who was very much alike the parent or with an abusive partner. Sometimes, they also had to struggle to have functional relationships with friends (Duncan and Browning 2009). The participants had difficulties in trusting other people and some had a low self-esteem, especially in social situations. Some had, because of their childhood experiences, learned to never show themselves to be vulnerable. Some participants had a large need for confirmation (Kadish 2015). Participants who had their own children could have difficulties in connecting to them, because of the lack of a connection to their own parent. They sometimes had to struggle to have a close relationship to their children (Foster 2010).

\section{Health and personal growth}

Some of the adult children had developed their own psychological problems, such as anxiety and depression (Foster 2010). There was fear regarding inheriting the parent's illness; a fear of themselves becoming mentally ill (Dunn 1993; Foster 2010; Wagenblass 2001). Participants who had parents with psychosis described a fear of becoming psychotic, both because of heredity and because of psychological effects from their childhood. The participants who had their own problems with depression and anxiety were afraid that they could develop a very serious mental illness (Kadish 2015). One participant described worry concerning suicidal tendencies in his genes; a fear of suddenly getting thoughts about ending his life (Murphy et al. 2015b). Some participants related that they, in their teenage years and as young adults, realized that their tough childhood had affected their development and also that the parent's illness made them vulnerable to developing mental illness themselves. Some felt fear because of this, while others felt strong; that they had become wise and mature because of their experiences (Van Parys et al. 2015). Some participants who had their own mental problems, indicated that this could increase their understanding of the parent and of the parent's illness. They could then turn to the parent and talk about their problems, because they knew that the parent understood (Petrowski and Stein 2016).

\section{Discussion}

This review set out with the aim of investigating experiences of having a parent with serious mental illness. With respect to the research questions, it was found that the childhood was 
experienced as deviant, with a home environment that was dysfunctional. In that home environment, the roles of parent and child were reversed, as the illness affected in a profound way the parent's ability to take care of the children (Duncan and Browning 2009; Dunn 1993; Kadish 2015; Mechling 2016; Parrott et al. 2015). This situation contravenes Article 19 of the Convention on the Rights of the Child, which states that children should be protected from "all forms of physical or mental violence, injury or abuse, neglect or negligent treatment, maltreatment" (Nationally and United Nations 1990). We further found that the home environment not only affected the children psychologically during their childhood, but also created difficulties that persisted into later adult life, including guilt, shame, alienation, social restrictions and problems with relationships. The correlation of childhood maltreatment and the risk of developing mental illness during adult life has been confirmed in previous studies (Hovens et al. 2015; Lee and Park 2018). It has further been found in a longitudinal study that of those who had experienced neglect and abuse in childhood, only about one fifth were assessed as being healthy functioning adults (McGloin and Widom 2001). Hence, we highlight the importance for clinicians of acknowledging these issues when encountering families where serious mental illness is present.

Furthermore, our findings demonstrate that the adult children during childhood experienced a need for support but were not fulfilled, and that the healthcare services had imbued them as relatives with fear and shame. These results match previous research, which indicates that mental health professionals demonstrate negative attitudes toward mental illness, especially in acute settings (Hsiao et al. 2015). We argue that mental health professionals need to adopt antistigma programs and to be critical of their own preconceptions. These issues need to be acknowledged, since the children as relatives, either during childhood or as adults, need to receive support rather than to be exposed to additional stigmatization (Baik and Bowers 2006; Foster 2010; Nilsson et al. 2015; Van Parys et al. 2015). Similarly, Askey et al. (2009) reported negative experiences from hospitals, which were described as being frightening, with staff that were not kind or helpful. In good agreement with this, Somers (2007) found that children wanted more information about the illness and advice about how to manage the situation. Only one of 37 children had at an early age received an explanation about the parent's illness from health care staff. We encourage clinicians to address these worrying findings in order to improve the experience of children as next of kin. The importance of educating family members is not restricted to instrumentally receiving 'good scores' from family members. Rather, previous studies have found that family interventions may result in the increased wellbeing of the whole family, as it relieves stress and reduces feelings of loneliness and burden (Pihkala
2011). In the modern era of web-based platforms, online support groups are becoming more widespread. Much research in other contexts has pinpointed the usefulness of internet-based support groups (Andersson and Titov 2014; M. Salzmann-Erikson and Hiçdurmaz 2017). However, we could not locate any studies that have investigated internet-based support groups for children of mentally ill parents. We stress the potential that such support groups might have and recommend this area in future research.

In our results, we identified some differences between those participants who had been children as next of kin to a parent with serious mental illness and those who are adult children as next of kin to such a parent. The latter have the mental capability to understand what is happening to their parent and thus are able to manage the situation from a more mature intellectual position. Another key difference is that adults, even though they might feel obligated to take care of their parent, are grown up, and are not dependent on an adult to have their own basic needs satisfied. This was explicitly apparent in the results, as some children feared for their security when the parent became physically abusive, mentally absent, or ignored their needs, such as for suitable or clean clothes (Baik and Bowers 2006; Duncan and Browning 2009; Dunn 1993; Wagenblass 2001). In contrast, the adult next of kin were able to distance themselves from the parent, even though they expressed what could be interpreted as moral obligations, which put psychological stress on them (Petrowski and Stein 2016; Van Parys et al. 2015).

Lastly, in similarity with Somers (2007), our review demonstrated that the children were convinced that the illness should be hidden and kept within the family. The children reported that the illness made the parent sad, worried and inactive, and that the parent withdrew into themselves. As a consequence, children tried to comfort and encourage the parent. This might explain some of the findings in previous studies, in which parents told that their children motivated them to get up in the mornings and gave them the strength to fulfill some of the child's needs (DiazCaneja and Johnson 2004; Jones et al. 2016). Hence, we interpret this phenomenon as being a reciprocal trigger, which might facilitate everyday living for both the parent and the child. However, a note of caution is due here, since previous studies have also demonstrated divergent findings, both in our review and in previous research. For example, the parent's illness affected their ability to fulfill their parental obligation, so in periods they were not able to care for themselves or to care for the children's needs (Duncan and Browning 2009; Nilsson et al. 2015; Parrott et al. 2015). Hence, our interpretation of positive reciprocal triggering must be studied more extensively.

In conclusion, the main target of this review was to investigate experiences of having a parent with serious 
mental illness. It was found that children who have grown up with the experience of a seriously mentally ill parent are profoundly affected by this. As children, they adopted the responsible role in order for the family to function; some parents had not been able to fulfill the children's basic needs. In addition, the dysfunctional home environment was something that as children they kept to themselves, which resulted in a sense of alienation. Thus, other adults in their surrounding became significant. The adult children to a parent with a serious mental illness described this parent as being their responsibility; they sometimes found that this situation restricted them and their ability to live an independent life and they were in need of therapy and/or support. Some adults had lingering effects from their childhood and suffered from relational issues or developed a mental illness themselves.

\section{Methodological Limitations}

Unfortunately, we were not able to include more than fourteen original studies, three of which are more than ten years old. It might be that if more original research that fulfilled our criteria for inclusion had been available, a more up to date view could have been presented. However, we found more than 4000 titles and all of them were reviewed, but gave us a good overview of the existing literature, and we argue that this minimized the risk of missing potentially relevant studies. A further limitation was that ten of the studies were conducted in the U.S., New Zealand or Australia, and three originated from E.U. countries, whereas only one study was conducted in Africa. Thus, the included articles were from countries with a well-developed economy, political stability and developed healthcare. This might have skewed the results compared with those that would have been obtained if studies from less stable countries had been included. Nine of the included articles were assessed as being of high quality according to the template and the remaining three as being of medium high quality. During the analysis, the sequential steps in the method of Evans (2003) provided us with clear guidance throughout the process. The decision to only include qualitative studies has, of course, affected the results. However, as we wanted to gain in-depth insights into the world of the participants' lived experiences, quantitative studies would not have answered the research questions. Applying qualitative analysis to health psychology is not without challenges, but it also methodologically completes the academic field (Lyons 2011).

\section{Compliance with Ethical Standards}

Conflict of Interest The authors declare that they have no conflict of interest.
Publisher's note: Springer Nature remains neutral with regard to jurisdictional claims in published maps and institutional affiliations.

Open Access This article is distributed under the terms of the Creative Commons Attribution 4.0 International License (http://crea tivecommons.org/licenses/by/4.0/), which permits use, duplication, adaptation, distribution, and reproduction in any medium or format, as long as you give appropriate credit to the original author(s) and the source, provide a link to the Creative Commons license, and indicate if changes were made.

\section{References}

Andersson, G., \& Titov, N. (2014). Advantages and limitations of Internet-based interventions for common mental disorders. World Psychiatry, 13(1), 4-11. https://doi.org/10.1002/wps.20083.

Askey, R., Holmshaw, J., Gamble, C., \& Gray, R. (2009). What do carers of people with psychosis need from mental health services? Exploring the views of carers, service users and professionals. Journal of Family Therapy, 31(3), 310-331. https://doi.org/10. 1111/j.1467-6427.2009.00470.x.

Baik, S.-Y., \& Bowers, B. J. (2006). Living with a mother with chronic depression: to tell or not to tell? Internet Journal of Mental Health, 3(1), 1-8. http://ovidsp.ovid.com/ovidweb.cgi?T=JS\&PAGE $=$ reference $\& D=$ psyc5\&NEWS $=\mathrm{N} \& A N=2006-13335-001$.

Diaz-Caneja, A., \& Johnson, S. (2004). The views and experiences of severely mentally ill mothers-a qualitative study. Social Psychiatry and Psychiatric Epidemiology, 39(6), 472-482. https:// doi.org/10.1007/s00127-004-0772-2.

Dunn, B. (1993). Growing up with a psychotic mother: a retrospective study. American Journal of Orthopsychiatry, 63(2), 177-189. https://doi.org/10.1037/h0079423.

Duncan, G., \& Browning, J. (2009). Adult attachment in children raised by parents with schizophrenia. Journal of Adult Development, 16(2), 76-86. https://doi.org/10.1007/s10804-009-9054-2.

Estabrooks, C. A., Field, P. A., \& Morse, J. M. (1994). Aggregating qualitative findings: an approach to theory development. Qualitative Health Research, 4(4), 503-511. https://doi.org/10.1177/ 104973239400400410.

Evans, D. (2003). Systematic reviews of interpretive research: interpretive data. Australian Journal of Advanced Nursing, 20(2), 22-26.

Ewertzon, M. (2012). Familjemedlem till person med psykossjukdom. Bemötande och utanförskap i psykiatrisk vård. Örebro Studies in Care Sciences, 35. https://www.diva-portal.org/smash/get/diva2: 523442/FULLTEXT01.pdf.

Ewertzon, M., Lützén, K., Svensson, E., \& Andershed, B. (2010). Family members' involvement in psychiatric care: experiences of the healthcare professionals' approach and feeling of alienation. Journal of Psychiatric and Mental Health Nursing, 17(5), 422-432. https://doi.org/10.1111/j.1365-2850.2009.01539.x.

Finfgeld-Connett, D. (2014). Use of content analysis to conduct knowledge-building and theory-generating qualitative systematic reviews. Qualitative Research, 14(3), 341-352. https://doi.org/ 10.1177/1468794113481790.

Foster, K. (2010). "You'd think this roller coaster was never going to stop": experiences of adult children of parents with serious mental illness. Journal of Clinical Nursing, 19(21-22), 3143-3151. https://doi.org/10.1111/j.1365-2702.2010.03293.x.

Gonsalves, C. A., McGannon, K. R., Schinke, R. J., \& Pegoraro, A. (2017). Mass media narratives of women's cardiovascular disease: a qualitative meta-synthesis. Health Psychology Review, 11 (2), 164-178. https://doi.org/10.1080/17437199.2017.1281750.

Hovens, J. G. F. M., Giltay, E. J., Spinhoven, P., Van Hemert, A. M., \& Penninx, B. W. J. H. (2015). Impact of childhood life events 
and childhood trauma on the onset and recurrence of depressive and anxiety disorders. Journal of Clinical Psychiatry, 76(7), 931-938. https://doi.org/10.4088/JCP.14m09135.

Hsiao, C.-Y., Lu, H.-L., \& Tsai, Y.-F. (2015). Factors influencing mental health nurses' attitudes towards people with mental illness. International Journal of Mental Health Nursing, 24(3), 272-280. https://doi.org/10.1111/inm.12129.

Jewell, T. C., Downing, D., \& McFarlane, W. R. (2009). Partnering with families: multiple family group psychoeducation for schizophrenia. Journal of Clinical Psychology, 65(8), 868-878. https://doi.org/10.1002/jclp.20610.

Jones, M., Pietilä, I., Joronen, K., Simpson, W., Gray, S., \& Kaunonen, M. (2016). Parents with mental illness-a qualitative study of identities and experiences with support services. Journal of Psychiatric and Mental Health Nursing, 23(8), 471-478. https:// doi.org/10.1111/jpm.12321.

Kadish, Y. (2015). Five women's recollections and reflections on being raised by a mother with psychosis. South African Journal of Psychology, 45(4), 480-494. https://doi.org/10.1177/ 0081246315581565.

Lee, S. Y., \& Park, C. L. (2018). Trauma exposure, posttraumatic stress, and preventive health behaviours: a systematic review. Health Psychology Review, 12(1), 75-109. https://doi.org/10. 1080/17437199.2017.1373030.

Lyons, A. C. (2011). Advancing and extending qualitative research in health psychology. Health Psychology Review, 5(1), 1-8. https:// doi.org/10.1080/17437199.2010.544638.

Mccann, T. V., Bamberg, J., \& Mccann, F. (2015). Family carers' experience of caring for an older parent with severe and persistent mental illness. International Journal of Mental Health Nursing, 24(3), 203-212. https://doi.org/10.1111/inm.12135.

McGloin, J. M., \& Widom, C. S. (2001). Resilience among abused and neglected children grown up-ProQuest. Development and Psychopathology, 13, 1021-1038.

Mechling, B. (2016). From shadows to hope: shared experiences of emerging adults who grew up with a depressed parent in the home. Issues in Mental Health Nursing, 37(4), 211-218. https:// doi.org/10.3109/01612840.2016.1140252.

Mignone, S., Zufferey, C., \& De Anstiss, H. (2017). Family experiences of caring for relatives who have received electroconvulsive therapy (ECT). Australian Social Work, O0(0), 1-12. https://doi. org/10.1080/0312407X.2017.1352001.

Murphy, G., Peters, K., Wilkes, L., \& Jackson, D. (2015a). Adult children of parents with mental illness: navigating stigma. Child \& Family Social Work, 36, 294-299. https://doi.org/10.1111/cfs.12246.

Murphy, G., Peters, K., Wilkes, L., \& Jackson, D. (2015b). Childhood parental mental illness: living with fear and mistrust. Issues in Mental Health Nursing, 36(4), 294-299. https://doi.org/10.3109/ 01612840.2014 .971385$.

Murphy, G., Peters, K., Wilkes, L. M., \& Jackson, D. (2016). Adult children of parents with mental illness: losing oneself. who am I? Issues in Mental Health Nursing, 37(9), 668-673. https://doi.org/ 10.1080/01612840.2016.1178359.

Nationally, A., \& United Nations. (1990). The convention on the rights of the child. The Philippine Journal of Nursing (60). https://doi. org/10.2307/4065371.

Nilsson, S., Gustafsson, L., \& Nolbris, M. J. (2015). Young adults' childhood experiences of support when living with a parent with a mental illness. Journal of Child Health Care, 19(4), 444-453. https://doi.org/10.1177/1367493513519296.

Nordby, K., Kjønsberg, K., \& Hummelvoll, J. K. (2010). Relatives of persons with recently discovered serious mental illness: In need of support to become resource persons in treatment and recovery. Journal of Psychiatric and Mental Health Nursing, 17(4), 304-311. https://doi.org/10.1111/j.1365-2850.2009.01531.x.

Parrott, F. R., Macinnes, D. L., \& Parrott, J. (2015). Mental illness and parenthood: being a parent in secure psychiatric care. Criminal Behaviour and Mental Health, 25(4), 258-272. https://doi.org/10. 1002/cbm.1948.

Petrowski, C. E., \& Stein, C. H. (2016). Young women's accounts of caregiving, family relationships, and personal growth when mother has mental illness. Journal of Child and Family Studies, 25(9), 2873-2884. https://doi.org/10.1007/s10826-016-0441-6.

Pihkala, H. (2011). Beardslees preventiva familjeintervention för barn till föräldrar med psykisk sjukdom Svenska familjers erfarenheter. Umeå: Umeå University.

Richert, T., Johnson, B., \& Svensson, B. (2018). Being a parent to an adult child with drug problems: negative impacts on life situation, health, and emotions. Journal of Family Issues, 39(8), 2311-2335. https://doi.org/10.1177/0192513X17748695.

Salzmann-Erikson, M., \& Dahlén, J. (2017). Nurses' establishment of health promoting relationships: a descriptive synthesis of anorexia nervosa research. Journal of Child and Family Studies, 26 (1), 1-13. https://doi.org/10.1007/s10826-016-0534-2.

Salzmann-Erikson, M., \& Hiçdurmaz, D. (2017). Use of social media among individuals who suffer from post-traumatic stress: a qualitative analysis of narratives. Qualitative Health Research, 27(2), 285-294. https://doi.org/10.1177/1049732315627364.

SAMHSA. (2016). Behind the term: serious mental illness. https:// nrepp.samhsa.gov/Docs/Literatures/Behind_the_Term _ SeriousMental Illness.pdf.

Sandelwski, M., \& Barroso, J. (2007). Handbook fo synthesizing qualitative research. New York: Springer Publishing Company.

Somers, V. (2007). Schizophrenia: the impact of parental illness on children. British Journal of Social Work, 37(8), 1319-1334. https://doi.org/10.1093/bjsw/bcl083.

Stjernswärd, S., \& Östman, M. (2008). Whose life am I living? Relatives living in the shadow of depression. International Journal of Social Psychiatry, 54(4), 358-369. https://doi.org/10. 1177/0020764008090794.

Treanor, L., Lobban, F., \& Barrowclough, C. (2013). Relatives' responses to psychosis: an exploratory investigation of low expressed emotion relatives. Psychology and Psychotherapy, 86 (2), 197-211. https://doi.org/10.1111/j.2044-8341.2011.02055.x.

Van Parys, H., Bonnewyn, A., Hooghe, A., De Mol, J., \& Rober, P. (2015). Toward understanding the child's experience in the process of parentification: young adults' reflections on growing up with a depressed parent. Journal of Marital and Family Therapy, 41(4), 522-536. https://doi.org/10.1111/jmft.12087.

Wagenblass, S. (2001). Biographische Erfahrungen von Kindern psychisch kranker Eltern. Praxis Der Kinderpsychologie Und Kinderpsychiatrie, 50(7), 513-524.

Weimand, B. M., Hall-Lord, M. L., Sällström, C., \& Hedelin, B. (2013). Life-sharing experiences of relatives of persons with severe mental illness - a phenomenographic study. Scandinavian Journal of Caring Sciences, 27(1), 99-107. https://doi.org/10. 1111/j.1471-6712.2012.01007.x. 